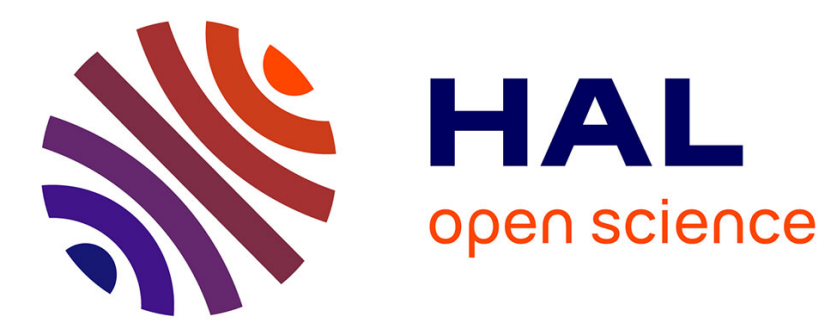

\title{
The Polymorphisms of the Chromatin Fiber
}

Jean-Baptiste Boulé, Julien Mozziconacci, Christophe Lavelle

\section{To cite this version:}

Jean-Baptiste Boulé, Julien Mozziconacci, Christophe Lavelle. The Polymorphisms of the Chromatin Fiber. Journal of Physics: Condensed Matter, 2015, 27 (3), 10.1088/0953-8984/27/3/033101 . hal03021375

\section{HAL Id: hal-03021375 \\ https://hal.science/hal-03021375}

Submitted on 24 Nov 2020

HAL is a multi-disciplinary open access archive for the deposit and dissemination of scientific research documents, whether they are published or not. The documents may come from teaching and research institutions in France or abroad, or from public or private research centers.
L'archive ouverte pluridisciplinaire HAL, est destinée au dépôt et à la diffusion de documents scientifiques de niveau recherche, publiés ou non, émanant des établissements d'enseignement et de recherche français ou étrangers, des laboratoires publics ou privés. 
TOPICAL REVIEW

\section{The Polymorphisms of the Chromatin Fiber}

Jean-Baptiste Boulé ${ }^{1,2+}$, Julien Mozziconacci ${ }^{2,3+}$ and Christophe Lavelle ${ }^{1,2 *}$

1- Genome Structure and Instability, CNRS UMR7196 - INSERM U1154, National Museum of Natural History, Paris, France

2- CNRS GDR 3536, University Pierre and Marie Curie-Paris 6, Paris, France

3- LPTMC, CNRS UMR 7600, University Pierre and Marie Curie-Paris 6, Paris, France

*Correspondence: lavelle@mnhn.fr / tel: +33 140794832

+ these authors contributed equally 


\begin{abstract}
In eukaryotes, the genome is packed into chromosomes, each consisting in large polymeric fibers made of DNA bound with proteins (mainly histones) and RNA molecules. The nature and precise 3D organization of this fiber has been a matter of intense speculations and debates. In the emerging picture, the local chromatin state plays a critical role in all fundamental DNA transactions, such as transcriptional control, DNA replication or repair. However, the molecular and structural mechanisms involved remain elusive. The purpose of this review is to give an overview of the tremendous efforts that have been made for almost 40 years to build physiologically relevant models of chromatin structure. The motivation behind building such models was to shift our representation and understanding of DNA transactions from a too simplistic "naked DNA" view to a more realistic "coated DNA" view, as a step towards a better framework in which to interpret mechanistically the control of genetic expression and other DNA metabolic processes. The field has evolved from a speculative point of view towards in vitro biochemistry and in silico modelling, but is still longing for experimental in vivo validations of the proposed structures or even proof of concept experiments demonstrating a clear role of a given structure in a metabolic transaction. The mere existence of a chromatin fiber as a relevant biological entity in vivo has been put into serious questioning. Current research is suggesting a possible reconciliation between theoretical studies and experiments, pointing towards a view where the polymorphic and dynamic nature of the chromatin fiber is essential to support its function in genome metabolism.
\end{abstract}




\section{Introduction}

DNA has been known as the carrier of genetic information for almost 70 years [1] and its double helical structure was elucidated more than 60 years ago [2]. However, the century-old question remains, as formulated by Thomas Morgan, American geneticist and 1933 Nobel Prize winner: "If the characters of the individual are determined by genes, why all the cells of an organism are not they the same?" If no one holds a clear answer yet, everyone agrees that some answer is to be found in the way DNA is structurally and dynamically organized in cells. As James Watson put it 10 years ago for the $50^{\text {th }}$ anniversary of his seminal paper with Francis Crick: "The major problem, I think, is chromatin... you can inherit something beyond the DNA sequence. That's where the real excitement of genetics is now" [3].

How and where is the regulatory information encoded, that enables the transcription of specific genes while silencing others? How can the same DNA molecules produce a different set of proteins (in different cell linages and/or cell cycle stages)? The complexity of biological systems has multiple origins, given the numerous actors involved, the combinatorial nature of their effects, and the variety of time- and space-scales to be considered. This topical review focuses on one aspect of this problem, namely the way DNA is packaged into the nucleus.

DNA is associated in vivo with histones (and some other non-histone proteins) to form a nucleoprotein complex known as "chromatin", a term introduced more than a century ago by German biologist Walther Flemming [4]. Today, it is commonly assumed that the polymorphic structure of chromatin and its dynamics holds a significant part of how the regulatory information is encoded in the nucleus. However, the rules allowing the cell to interpret this "epigenetic" information are far from being elucidated. The term "epigenetic information" raises some debates that are beyond the scope of this mechanistic review, but the reader interested in this question should refer for instance to [5]. Regardless of this debate, deciphering the structural organization of the chromatin fiber is an important topic to study as a step towards describing the relationship between chromatin organization and genome function. As was true for the elucidation of DNA structure and the genetic code, understanding the consequence of chromatin structure on transcription in space and time requires a combination of experimental and theoretical approaches [6, 7]. Amazingly, after more than 40 years of intense efforts, not only the structure of the so-called "30nm chromatin fiber", which is drawn in every molecular biology textbooks, remains elusive [8-11], but its existence in vivo is still highly controversial [12-14].

Here, we wish to provide an historical perspective of a particular field of chromatin studies that focuses on the $30 \mathrm{~nm}$ scale. By giving a critical assessment of the experimental and theoretical work that has been done to prove or disprove the existence of such structure in vivo, we aim at understanding better what are the challenges ahead in the field and what could be some of his promises. 


\section{The birth and rise of the "30nm fiber"}

Eukaryote chromatin is characterized a minima by the wrapping of nuclear DNA around histone proteins, assembled in nucleosomes. Histones and chromatin remodeling activities are highly conserved in evolution, pointing towards the universality of the mechanisms developed by eukaryotic organisms to manage genomic information.

Under appropriate conditions, the beads-on-a-string nucleosomal array can fold into a compact structure (Figure 1). The first images of condensed nucleosomal arrays showed fibrous structures of roughly $30 \mathrm{~nm}$ in diameter [15]. Because they were obtained in presence of physiological concentrations of salt and highly dependent on the presence of magnesium, this so-called "30nm fiber" was soon considered as the next packaging level of DNA after the nucleosome and is since depicted as such in all biology textbooks addressing chromosome folding. The nucleosome solution to the problem of DNA packaging seemed like an elegant one, as nature can offer, and also had the promise of allowing us to explain a lot about genome metabolism. These first studies triggered modeling efforts, and before nucleosome was even characterized, continuous supercoiled nucleo-histone models of chromatin were suggested [16]. Evidences for a discrete DNA-histone complex were soon obtained from a variety of experimental approaches: nuclease digestion patterns [17], biochemical and X-ray diffraction studies $[18,19]$ and electron microscopy [20, 21] (see [22] for an historical perspective). These studies opened the way to various experimental and theoretical studies aiming at deciphering the in vivo folding of these "beads on a string". In the 70s, first observations of isolated chromatin fibers ex vivo lead to the popular solenoid model, in which nucleosomes are arranged helically, and the linker DNA follows the same helical path established by the nucleosome [23-25]. These first efforts revealed the importance of some key parameters for the formation of a $30 \mathrm{~nm}$ fiber, especially the dependence on magnesium ions and the need for an internucleosomal linker histone H1. In H1-depleted extracts, increasing salt concentration could trigger condensation of nucleosome arrays, but these arrays were irregular and the entry and exit site of DNA in nucleosome appeared random [25]. Subsequent in vitro work in the 80s confirmed that the only way to get regular arrays was to incorporate histone $\mathrm{H} 1$ into the reconstitution assay. Alternative to the solenoid model was also proposed, such as the twisted ribbon, first proposed by Worcel \& al [26] and argued for later on by Woodcock \& al [27] (Figure 2). Further experiments on isolated chromatin revealed however that the fibers observed by Woodcock $\&$ al are left-handed helices of stacked nucleosomes, not a twisted ribbon [28].

In 2004, interpretation of electron micrographs and digestion data obtained from regular nucleosome arrays reconstituted on a synthetic repeated DNA sequence gave support to a two-start helix organization of this synthetic chromatin fiber, in which internucleosomal DNA linker crosslinks the arrangement of nucleosomes [29]. X-ray structure of a tetranucleosome reconstituted on a similar repeated-sequence array also supported this organization [30]. It is worth noting that these studies are based on reconstituted fiber using purified nucleosomes on the so-called "601" sequence. This sequence 
was originally obtained by an in vitro selection (selex) approach to address the ability of the sequence itself to be a primary determinant of the position of nucleosomes on DNA. The set of 147-bp sequences reported in this seminal study by Jonathan Widom's group allowed in vitro positioning of nucleosomes on DNA more efficiently than with any natural sequence known [31]. Among this set, the 601 sequence has been used extensively since. In vitro, nucleosomes are positioned on this sequence at only one dominant position at equilibrium, and this property has been an interesting prerequisite for high resolution structural and crystallography studies. This artificial system has been very useful to obtain homogenous fibers, allowing testing fine parameters for creating a regular fiber structure. It allowed for example determining for how the length of the DNA linker affects the possible conformations of the fiber (see below). Although the DNA repeat used was entirely artificial, it is interesting to note that the structures obtained could be relevant to chromatin regions covering tandem repeats in eukaryote genomes, e.g. pericentromeric satellite DNA, which monomers have a size compatible with the wrapping of one nucleosome or even chromatosome per monomer [32].

In the two-start helix organization obtained with the 601 sequence, internucleosomal DNA linkers cross-link nucleosome arrangements along the fiber. Evidence for a compatible type of arrangement had been obtained using ionizing radiation on mitotic chromosomes [33]. Therefore, crossed-linker models slowly supplemented the historical solenoidal model. Cross-linked fibers can be modelled with a two-angle [34] or a three-angle [35, 36] model; these modeling issues are discussed below.

\section{From the 80's hand-made models to in silico chromatin fibers}

Worcel and colleagues first addressed the 3D modeling of sophisticated chromatin structures in the 80's using plastic tube and beads (Figure 2). These authors reconstituted the original solenoidal model [24]. They also proposed a second model, which was compatible with EM observation of isolated fibers, but also consistent with the measured DNA linking number within chromatin [26]. Later, several alternative models were proposed with three [37] and two [28] helices. All these models were compatible with available experimental data such as EM images, X-rays diffraction patterns and dichroism values. Hardmodels provide a practical and powerful tool to test new hypotheses, and as such, new attempts were regularly made to build increasingly refined models [38].

The development of computers and related 3D applications led chromatin modelers to switch from their scaled hard models to in silico ones, which add the possibility to introduce dynamic parameters. The first simple geometrical model was published in 1993 [34]. Woodcock et al. proposed that the geometry of native chromatin fibers extracted from nuclei could be simply described using two angles. The first angle (alpha) is the angle in between the entry and exit linker directions of a single nucleosome. The second one (beta) corresponds to the phasing angle in between consecutive 
nucleosomes and is depending on the DNA length joining the two nucleosomes, due to the helical nature of the DNA molecule. This model assumes that DNA linkers are straight due to the high bending stiffness of naked DNA. The two-angle model has been used through the following years as a toy model, which properties can be calculated analytically. In the early 2000's, Victor and colleagues introduced DNA mechanics in this geometrical model. The main proposition made from these studies was that the length of the linker DNA constrains the type of structures that the chromatin fiber can adopt, and therefore its mechanical properties, such as rigidity in bending, twisting or stretching [39]. It raised the interesting idea that nucleosomal density can help regulate fiber mechanical properties. Such modeling showed for instance an intriguing property of two starts chromatin fiber structures: they can be elongated without introducing any mechanical constrains on the DNA linkers [40]. The two-angle model has also been used in Monte-Carlo simulations in order to better understand the influence of energy in the folding of the chromatin into a compact fiber [41-44]. The presence of the linker histone H1, and its effect on the fiber compaction through the stem like structure that it induces at the entry/exit of each nucleosomes, has been investigated mainly by modifying the alpha angle, as seen on electron microscopy images [45].

Despite the success of the two-angle model for theoretical calculations and systematic searches for specific structures $[39,46,47]$, new experimental evidences challenged the idea that the DNA linker is straight in vivo. Indeed, structures provided by these models showed a maximal compaction of 6 nucleosomes per $10 \mathrm{~nm}$, corresponding to the compaction estimated for isolated fibers in vitro [28], and may be assumed to be relevant to describe chromatin during interphase. However, the linear density of the fiber in metaphasic chromosomes must be higher than the one of this latter structure. Namely, the fiber compaction is thought to increase from 6 to 10 nucleosomes per $10 \mathrm{~nm}$ during the last compaction step of prophase [48], which is twice as much as the most compact structure that can be described using the two angle model $[49,50]$. Different models have been proposed to account for this compaction. In 1998, Daban and Bermudez proposed a first space-filling model of highly compact chromatin [50]. In this purely geometric model, DNA mechanical properties were not taken into account. They proposed solutions for the structures of compact fibers containing 4, 5 or even 6 nucleosome interdigitated helices wrapped together. Interestingly, the dimensions measured for a short $177 \mathrm{bp}$ repeat length fiber reconstituted in vitro on a 601 repeated sequence recently gave experimental support to the 5 start structure for short linker DNA length [51]. In another attempt to modify the two-angle model in order to attain the compaction expected in metaphasic chromosomes, Mozziconacci et al. proposed that the nucleosome might be able to undergo a conformational change, similar to the gaping of an oyster [36]. This added flexibility on the nucleosome particle, which added a new degree of freedom to the twoangle model, allowed to design more compact in silico models of the chromatin fiber by enhancing the stacking interactions between neighboring nucleosomes [35].

In order to make a physically realistic model of the DNA linker deformations, chain-like linker models were developed. The first such model including DNA mechanical constraints was used to explain direct physical micro manipulation of single fibers [52]. A more sophisticated model, including 
explicitly the electric charges on the surface of DNA and histones was later developed. The so-called Discrete Surface Charge Optimization (DiSCO) model was used to investigate electrostatic effects in salt induced compaction of the fiber and the role of histone tails in nucleosome/nucleosome interactions [53-57]. However useful they proved to investigate chromatin dynamics, none of these models allowed fibers to reach compaction comparable to the one expected in metaphasic chromosomes [48] or in vitro on reconstituted fibers [51]. More efforts will therefore be needed on the physical modeling part in order to account for all the experimental observations.For more details about recent models incorporating the role of electrostatic interactions in DNA and chromatin compaction, the reader should refer to [58-61].

\section{A nomenclature for compact fiber structures}

A plethora of structures have been proposed over the years to account for experimental observations of chromatin fibers from various sources. To help the comparison between these structures, we propose here a simple nomenclature, adapted from [62]. This nomenclature uses one number and one letter: the number refers to the number of starts of the helix while the first letter, capital $\mathrm{R}$ or $\mathrm{L}$, refers to the handedness of the helix. All homogeneous models with the DNA linker placed inside the fiber and containing stacked nucleosomes can be classified using this nomenclature. For example, the two-start helix proposed by Richmond and colleagues from the crystal structure of a tetra-nucleosome is the $2 \mathrm{~L}$ fiber whereas the one proposed by Robinson and co-workers is the 5R. Importantly, Robinson \& al. refer to their structure as a one-start structure (according to the DNA path around the fiber axis), whereas according to our nomenclature, it is a five-start structure, the $n+5^{\text {th }}$ nucleosome being stacked on the $\mathrm{n}^{\text {th }}$ one. An exhaustive classification of all the proposed models for homogeneous fibers according to this nomenclature is presented in figure 3.

We would like to point out here that alternative models of the chromatin fiber have been proposed that do not fall into this classification. This is the case of the twisted ribbon model [63] and its derivatives. These latter models assume that nucleosomes are not identical within a fiber but that dinucleosomes are the elementary unit [64-66]. These models have been marginally supported by the analysis of nuclease digestion patterns in nuclei [67] and may be relevant when the H1 nucleosomes ratio is close to one half instead of one. For the rest of this review, we will only refer to the structures referenced in our table. Since all their structures were achieved using different sources of material, and through different methods of examination, given our level of knowledge of chromatin structure in vivo, there is no reason to assume that some structures are more relevant than others to describe native chromatin. We should rather consider that chromatin is likely to adopt, in a certain genomic or physiological context, structures falling into some of these categories. 


\section{Relation between the linker length and the diameter of the chromatin fiber}

The length of the DNA linker between nucleosomes was early assumed to be a relevant parameter to correlate 1D data (nucleosome positioning on the DNA sequence) with 3D structure of the chromatin fiber. The methodology allowing to gather nucleosome spacing as a population average, based on the availability of nucleases cutting the DNA linker while leaving intact nucleosome protected DNA, has been available since the late 1970s [17]. This methodology basically delivers the spacing of nucleasesensitive regions on DNA, or nucleosome repeat length (NRL).

In the context of our topic, what have we learned about the relationship between the 1D structure and the 3D structure? In 1986 Williams et al. measured the fibers diameters in situ using X-rays diffraction patterns of intact nucleus. They used seven different cell types, from different organisms, with NRL equal to 191, 194, 198, 206, 225, 233 and 240 bp (Figure 4a). In this study, very specific cell types, containing almost entirely silent chromatin, had to be used in order to get sharp NRL measurements and isolated fibers homogenous in aspect. It was observed that longer NRL leads to bigger fiber diameters, up to $40 \mathrm{~nm}$. They conclude that their result is only compatible with one 3D model: the two starts cross-linker model. The same conclusion was drawn from EM and X-rays measurements on isolated fibers (Figure $4 b$ ).

Daniela Rhodes and colleagues challenged experimentally the link between nucleosome spacing and the structure of the chromatin fiber 20 years later. In their case, they used chromatin reconstituted in vitro from purified nucleosomes and, using perfect tandem repeats centered on the 601 positioning sequence as a source of DNA. They measured the dimensions of such reconstituted fibers containing the H1 linker histone with varying linker lengths and observed a step like relationship: the diameter of the fiber increased from 33 to $44 \mathrm{~nm}$ as the NRL exceeded $207 \mathrm{bp}$ [51] (Figure 4c). Their findings exclude the possibility that these reconstituted fibers are $2 \mathrm{~L}$ helices. The only structure that could be inferred from the measured dimensions for all NRL was Daban's five start (5R) structure. These news results, based on old concepts, led to the development of new fibers models. Wong et al. proposed an explicit all-atom structure for each linker length used in Rhodes experiment and concluded that all previously models, including the two start cross linker structure are relevant [62]. The length of the linker connecting nucleosomes determines therefore which structure is allowed to form. At the same time, Wu et al. proposed an analytical calculation of the fiber dimensions [68]. They used their formula to fit Rhodes' data and proposed that the chromatin fiber can switch from a helical ribbon to a crosslinker model depending on the linker length. Depken and Schiessel proposed a geometrical model in which nucleosomes are staked. Based on the nucleosome shape, they proposed that chromatin fibers were made from the wrapping of either 5 or 7 columns of nucleosomes, for linkers respectively shorter than 210 bp or longer than 184 bp [69]. Here again, the same experimental evidences led different groups to different conclusions. However, a common feature of these studies was the need for different 
structures to account for experimental observations. This polymorphism has also been confirmed in vitro for fibers reconstituted with NRL of 167 and 197 bp by Daniela Rhodes' group in presence of H5 linker histones [70].

New experiments based on these reconstituted fibers were therefore needed to address the structural models. Tim Richmond's lab conducted an elegant biochemical experiment in that direction $[29,30]$. They reconstituted chromatin fibers using repeats of the 601 sequence with a NRL of $207 \mathrm{bp}$, H1 linker histones, and recombinant histones modified to allow induced covalent attachment between stacked nucleosomes exclusively. After crosslinking and digestion of the DNA linkers, they observed two columns of staked nucleosomes per fiber, in support of the two-start model. Further and possibly definitive support to the two-start model has been very recently brought by high resolution TEM studies on in vitro reconstituted tetranucleosomal units containing linker histones [66].

Due to the similitude of the measurement done in situ in isolated fibers and on reconstituted materials, it is tempting to hypothesize that the proposed structures, might also be relevant in vivo, when the linker histone is present to a one to one ratio [71]. Another prediction of the Wong et al. model is that the nucleosome tilt angle in the fiber (i.e. the angle between the fiber axis and the nucleosomal super helix axis) must vary for different NRLs: for $177 \mathrm{bp}$, the fiber adopts a 5R structure with a 35 degrees angle tilt; for $187 \mathrm{bp}$ the fiber adopts a 4R structure with 30 degrees angle tilt, for $197 \mathrm{bp}$ the fiber adopts a 3R structure with 25 degrees angle tilt and for 207 bp the fiber adopts a $2 \mathrm{R}$ structure with 20 degrees angle tilt. These values are similar to older measurements inferred from observations of isolated fibers, which concluded that the tilt varies from 33 for a NRL of 177 bp to 26 for a NRL of 207 bp [28].

\section{The nucleosomal repeat length in vivo as an imprint of the chromatin fiber structure?}

If chromatin folds in vivo, or at least in discrete regions of the genome and in ways reminiscent to the "ideal" structures inferred from reconstitution studies, the spacing between nucleosomes should be quantized in these regions and the NRL should also be close to multiples of the helical periodicity of the DNA molecule [72]. This idea has been further confirmed by Jonathan Widom, who noticed that NRLs measured in vivo, using MNase digestion data, were compatible with both these requirements, pointing to a series of NRL every 10 bp between about 157 to 237 bp [73]. This intuition is also validated by data obtained by in vitro reconstitution of homogenous chromatin fibers and in silico modeling, as they are the only values allowing an homogenous fiber to be made (in the presence of the linker histone H1), other values being hardly compatible with a homogenous fiber [62].

In the last decade, high throughput DNA sequencing technologies have allowed to move from studying nucleosome occupancy profiles at given loci to mapping preferred positions genome wide in a population of cells in several model organisms (budding yeast [74]), the worm C. elegans [75]) and in 
human cell lines [76]). Measured in bulk, the NRL depends on the organism considered, the level of differentiation in the case of human cells or even the locus considered [75, 76].

Because of its tractability, budding yeast has been widely used to study nucleosome in fine details. In particular, enzymatic digestion of non-nucleosomal DNA with MNase followed by highthroughput sequencing of nucleosome-protected regions allows determining statistical positions of nucleosomes genome wide. Nucleosomes appear to occupy certain positions on DNA preferentially, in particular close to the start of protein coding genes. Occupancy around or in the promoter may vary, depending on the type of transcriptional regulation of the gene [77], but the nucleosomes covering gene bodies appear to be separated regularly by approximately $167 \mathrm{bp}$, with the +1 close to the transcription start site. Nucleosome positioning data have fed numerous studies aimed at understanding what from the intrinsic role of DNA sequence versus active mechanisms can explain how yeast organizes its chromatin. This debate is not yet solved, since there are strong arguments in favor of both mechanisms being important [78].

In the emerging model for nucleosome positioning, known as "statistical positioning", nucleosome spacing is due to steric repulsion between nucleosomes and to the presence of nucleosome excluding barriers on the genome (e.g. at promoters, either due to intrinsic sequence properties or because of the presence of bound proteins). However, new experimental evidence recently challenged the "statistical positioning" model [79]. We recently proposed that the regular spacing between nucleosomes could be better explained by adding attractive interactions between nucleosomes [80]. In this model, these attractions are due to the fact that nucleosomes are stacked in regular chromatin fibers. In a self-reinforcing mechanism, regular nucleosome spacing promotes in turn nucleosome stacking. This model can quantitatively account for the nucleosome spacing observed in Saccharomyces cerevisiae.

A recent study made in two human cell lines from the hematopoietic differentiation lineages ( $\mathrm{T}$ lymphocytes and granulocytes) explored the quantization of nucleosome spacing in details [76]. The main outcome of this study is that the NRL is changing during the differentiation of granulocytes from 203 bp to $193 \mathrm{bp}$. These two NRL would correspond to two different fiber structures in our nomenclature: respectively the $2 \mathrm{~L}$ and the $3 \mathrm{~L}$. We will leave the reader with the speculative idea that these observations can point to a role of the chromatin fiber structure in cell differentiation.

The role of the histone linker H1 in chromatin structure and nucleosome spacing has also been recently reappraised. For a thorough review of this critical issue, we refer the reader to the excellent review by Woodcock et al [71]. As noted earlier in this review, the effect of $\mathrm{H} 1$ in in vitro reconstruction experiments has suggested its essential role in chromatin compaction. A brief summary of the main observations and outstanding questions about the role of the linker $\mathrm{H} 1$ goes as follows. H1 stoichiometry relative to nucleosomes varies considerably, according to the cell type and the organism considered. In the limited amount of cell types in which it has been measured, the H1/nucleosome ratio varies from about $0.25 \mathrm{H} 1 /$ nucleosome in yeast, which does not express a canonical H1 but still possesses a linker 
histone (Hho1), to $1.3 \mathrm{H} 1$ /nucleosome in rat glia. From these data, there is an exquisite relationship between the $\mathrm{H} 1$ ratio and the NRL, pointing to the importance of H1 in NRL quantization in the cell [71]. The variability of the $\mathrm{H} 1 /$ nucleosome ratio questions nevertheless the concept of the $30 \mathrm{~nm}$ fiber structure driven by $\mathrm{H} 1$ architectural properties. In addition, lowering the expression of H1 isotypes in mouse ES cells leads to a reduction of the NRL as expected, but has however very little effect on gene expression and rather exhibits effects on methylation patterns of imprinted genes [81]. These results have therefore challenged the idea that $\mathrm{H} 1$ acts as a general repressor of chromatin activity, and rather point to a subtler epigenetic role. In addition, lowering the H1/nucleosome in these cells does not induce a fuzzier NRL quantization, indicating that the effect of lowering $\mathrm{H} 1$ on chromatin structure in vivo is gradual and affects chromatin globally [81, 82]. Last but not least: linker histones incorporation was shown to have very little effect on the mechanical properties of chromatin fibers [83].

\section{The case of repeated sequence to study chromatin structures formation}

Regarding repeated sequences in multicellular organisms, it is interesting to remember that pericentromeric alpha satellites from the African Green Monkey (AGM) genome served as early models to test quantization of nucleosome positioning. The reason was mainly technical, as the AGM genome served as a fairly easy source of abundant material and the repeated nature of the region allowed analysis of the region by restriction digest and gel analysis, which was the technique of choice at the time. Results from several groups led to a heated debate between proponents of quantization of nucleosome repeats according to the $171 \mathrm{bp}$ repeats and proponents of random positioning [84-88]. In fact, results converged towards mixed results, where some of the population of nucleosomes seemed quantized and other not.

By using a combination of modeling and analysis of genome wide data of nucleosome positioning in mouse, Teif and colleagues reassessed and confirmed these results, showing both that direct and indirect sequence-specific effects dominate at cis-regulatory regions, but that NRL of the constitutive heterochromatin assembled on centromeric repeated regions appear to be mostly determined by the chromatin context (which includes density of linker histone H1, of structural protein HMG1, histone modifications) [89]. In other words, the NRL in these regions is not mainly determined by the size of the repeat, but by the nature of chromatin assembled around it. Whether this corresponds to a particular chromatin structure is likely but still needs to be determined. Because of problems posed by repeated sequences for alignment on reference genomes from short read NGS data, there is currently still a lack of data concerning nucleosome organization in repeated regions from other large genomes. Several recent NGS data however confirm quantization of nucleosome spacing in human alpha satellites [90], revitalizing the interesting possibility of a coevolution of repeated sequences, chromatin structure and function. Experiments reported by Teif and colleagues point to the necessity to address however each repeat type separately [89]. In that sense, it is interesting to remember that most in vitro reconstitution 
assays are based on repeats of positioning sequences, reinforcing the idea that they are mostly models of repeated sequence organization rather than general chromatin models.

If different NRLs correspond indeed to different fiber structures, one might ask what would be the function of such a polymorphism. It is tempting to hypothesize that chromatin adopts various structures, adjusted locally by differential nucleosome spacing [91]. Cells could use nucleosomes positioning as a way to regulate the physical properties of the different parts along the genome. In this frame, it is interesting to speculate that the spacing in between nucleosomes in some repeated regions has evolved in order to favor the formation a specific 3D chromatin fiber structures with defined mechanical and/or biochemical properties. Futhermore, interdigitation of chromatin fibers suggests a relation between local NRL and interfiber interaction; one might therefore ask whether self-association of repeated sequences could be favored by local NRL management by the cellular machineries. Similar nucleosome spacing could be in turn important to facilitate homologous regions pairing, chromosome territory organization, etc...

\section{The $30 \mathrm{~nm}$ fiber in vivo: chasing a phantom?}

The wealth of experimental data and apparently contradictory models produced over the last 40 years for the $30 \mathrm{~nm}$ chromatin fiber illustrates the difficulty of observing and understanding this macromolecular structure. Namely, for each model produced that is supported by some data, other data have often arisen to contradict it, explaining why no consensual picture exists yet [10,92]. Difficulties are mainly from two sources: first, there is obviously an "extrinsic" problem due to experimental limitation. It's indeed hard to get in vivo data, and isolated fibers should be regarded with caution [27]. Then, there is also an "intrinsic" and probably even more limitative problem due to the fact that chromatin is by itself a polymorphic and dynamic structure. It is indeed not only a convenient way to pack two meters of DNA into the nucleus, but also definitely has a regulatory role in DNA metabolism and must therefore exhibit structural polymorphism and transient local structural rearrangements, both making it a difficult entity to grasp.

The main obstacle to confirming the existence of a $30 \mathrm{~nm}$ fiber in vivo has been its lack of direct observation in vivo. On the epistemological level, this absence of proof is not proof of absence, therefore unsuccessful attempts to develop experimental approaches allowing direct proof of nucleosomes folding into a $30 \mathrm{~nm}$ fiber in vivo cannot be regarded as a final proof of the non-existence of the fiber. Nevertheless, as more refined microscopy approaches still fail at catching the elusive structure, one has to wonder how to reconcile seemingly two completely opposite views. New experimental approaches have been developed for direct observation of the fiber and their result keep questioning the existence of the fiber. In particular, cryo-EM observation of mitotic chromosomes fails to reveal any substructure above $11 \mathrm{~nm}$ packing of nucleosomes. These studies led to a model of chromosome folding 
corresponding to a melt polymer with strong inter-fiber nucleosome interaction of comparable strength to intra-fiber interactions, resulting in the mixing of nucleosomes [93]. Their idea is the following: in a diluted chromatin context, intra-fiber interactions dominate, allowing the formation of $30 \mathrm{~nm}$ structures, and this situation is equivalent to the conditions in which chromatin fibers are reconstituted in vitro. At high chromatin concentration, as expected in the cell, inter fiber interactions dominate, leading to the formation of a melt polymer. This model however does not preclude the existence of a $30 \mathrm{~nm}$ fiber in interphase nuclei, since the melt polymer model would also predict that $30 \mathrm{~nm}$ fibers could form transiently from extended chromatin conformation (during a transcription event for example) to the melt state[94].

Bazett-Jones and colleagues have used energy spectroscopic imaging (ESI) for improved chromatin contrast to hunt for evidence of higher order organization of chromatin inside the cell. They fail to observe any hint of $30 \mathrm{~nm}$ chromatin structure in a range of cell types, and no $30 \mathrm{~nm}$ structure could be visualized within compact chromatin regions [95, 96]. Fixation by cryo-methods like high pressure freezing used in cryo-microscopy produce vitreous ice and is considered producing samples in a close-to-native state. However, as pointed out by Bian and Belmont [97], freezing rates are in the order of milliseconds, which is still slow compare to FRET/FCS measurements of trinucleosome decompaction [98]. In addition, effect of freezing on the helical periodicity of DNA is unknown, and a change in the DNA pitch would be likely to unfold any higher order structure. Concerning the ESI studies, formaldehyde fixation and immunostaining procedures used in ESI have been previously shown to significantly affect chromatin structures [99]. The "10 nm chromatin fibers" that Bazett-Jones and colleagues observe, especially in ES cells, could be the result of the swelling and extraction of nucleosomal filaments. Caution should therefore be taken in drawing definite conclusions based on these observations.

\section{Trying to reconciliate the data: towards modeling a dynamic and polymorphic chromatin structure}

According to the polymer melt model, compaction of the chromatin inside the cell favor interfiber rather than intrafiber interactions, the latter being favored at low chromatin concentration, for example during in vitro reconstitution experiments. There is some experimental support in favor of internucleosomal interactions. The Hayes' group developed an ingenious nucleosomal array system to probe for internucleosomal interactions in vitro, with which they could show that $\mathrm{H} 3$ and $\mathrm{H} 4$ nucleosome tails mediate internucleosome interactions that increase significantly at $\mathrm{Mg} 2+$ concentrations $>2 \mathrm{mM}$. Their work draw also attention to the fact that posttranslational modifications play an important role in affecting the strength of these interactions, which has important consequences on compaction of 
chromatin and therefore on higher order structure formation [100]. Importantly, their results are both compatible with nucleosome interaction within a fiber or between different fibers [101-103].

Differences in nucleosome/nucleosome interactions might also explain the different results obtained by the Richmond [29] and Li labs [66] on one end and the Rhodes lab [51] on the other hand, on the structure of a nucleosomal fiber reconstituted on a 177 bp 601 array. The resulting diameter and start organization of the structures are not in agreement. Such a disagreement could be explained either by experimental short comings, or by the fact that they used two different histone sources: whereas the Richmond and later on the Li lab use recombinant Xenopus histones which are non-modified, the Rhodes lab uses purified chicken erythrocytes histones which might have different physical properties. The role of internucleosomal interaction on the chromatin fiber has also been investigated in silico using Monte Carlo simulations [44, 104]. Modeling the chromatin fibers, they showed that increasing nucleosome interaction energies promotes the nucleosome fibers to become interdigitated, in particular with large NRLs (>206 bp). Adding the effect of nucleosome post-translational modifications or specific proteins binding (e.g. HP1, MECP2 or HMG proteins) on nucleosome interaction energies will be of great interest in the future, in order to understand how such modifications of the chromatin fibers drive local fiber dynamic and regulation of metabolic processes like transcriptional regulation.

Breaking from a history of static structural models of chromatin organization, the trend in the chromatin field is rapidly moving towards far more dynamic models, which take into consideration biochemical kinetics. At the nucleosome level, in vivo FCS studies by the Maeshima's lab indicate that nucleosomes of interphase chromatin show local fluctuations (50 nm per $30 \mathrm{~ms}$ ) caused by Brownian motion, and suggest that the highly dynamic nature of the fiber facilitate biochemical transactions like genome scanning by DNA-binding factors $[105,106]$. The modern emphasis on the dynamic nature of chromatin therefore raises new challenges for the field in years to come. Both the polymer melt model promoted by the Maeshima's and Eltsov's groups suggest that transient extraction of the chromatin fiber from the melt during biochemical transactions (like transcription) can lead to formation of single-fiber higher order structures compatible with the ones observed in vitro. What is therefore the dynamics of these structures, and how are they affected by histone modifications, histone linker or binding of other specific factors?

\section{Conclusion}

DNA being almost never naked in the nucleus, DNA metabolism is first chromatin metabolism, which makes chromatin fiber a distinct level of cellular regulation. More than a simple barrier to DNA accessibility, chromatin has a functional role that relevant models should help us to understand. Chromatin faces electrostatic, elastic and topological constraints that have to be integrated in multiscale models including both structural and dynamical parameters [107-109]. The three dimensional chromatin 
structure depends on distinct but highly coupled parameters: DNA sequence, nucleosome spacing and the regularity of this spacing $[60,62,110]$, histone modifications (through variants incorporations [111, 112] and/or post-translational modifications [113]), nucleosome conformation (through DNA fluctuations at the entry/exit sites and potential deformation of the core particle itself [36, 114]), interactions within the fiber (through histone tails interactions [59] and DNA elasticity and topology [115]) and non-histone proteins possibly present (i.e. HMG proteins, HP1 in heterochromatin, TRF1/2 in telomeres). However, we have to keep in mind that the dynamic at which chromatin structures form and unfold is unknown, and therefore, it is yet impossible to ascertain the lifetime of these structures, if they occur in vivo. Some might be short-lived and linked to a biochemical event (e.g. transcription), and some might be long-lived enough to be traced experimentally. To address these questions, it is likely that the field will gain from continuing modeling efforts, but also from molecular biology approaches aiming at designing synthetic in vivo reporter assays based on engineered synthetic chromatin substrates able to capture and quantify transient dynamic interaction.

As the same time, massive sequencing techniques now allows inferring the statistical distribution of nucleosomes genome-wide in a given population and in a given environment. In several tractable model systems, budding yeast in particular, expression data and other "epigenomic" information (e.g. histone modifications maps) can be correlated to these nucleosome maps [116]. Another genome wide structural scale is being deciphered from chromosomal contact map obtained via complex molecular biology techniques and bioinformatics methods (loosely referred to as "chromosome conformation capture" methods (e.g. [117]). However, the "meso" scale in which studies of the 30nm fiber is relevant is still lacking in this molecular description of the cell, which is still a rather static one.

We hope that in the next years, people will manage to fill this gap and get high resolution in vivo imaging of chromatin fibers, endly providing a clear picture to the holy grail seeked by "chromatin knights" since decades!.

\section{Acknowledgement}

This work was supported by a grant from UPMC (CVG1110). Such a chapter being obviously much more subjective than exhaustive, we apologize to any of our colleagues whose work could not be cited due to lack of space.

\section{References}


1. Avery, H.E., MacLeod, C.M., and McCarty, M. (1944). Studies on the chemical nture of the substance inducing transformation of pneumococcal types. J Exp Med 79, 137-158.

2. Watson, J.D., and Crick, F.H. (1953). Molecular structure of nucleic acids; a structure for deoxyribose nucleic acid. Nature 171,737-738.

3. Watson, J.D. (2003). Celebrating the genetic jubilee: a conversation with James D. Watson. Interviewed by John Rennie. Scientific American 288, 66-69.

4. $\quad$ Flemming, W. (1882). Zell substanz, Kern und Zelltheilung., (Leipzig: Vogel).

5. Ptashne, M. (2007). On the use of the word 'epigenetic'. Curr Biol 17, R233-236.

6. Mozziconacci, J., and Lavelle, C. (2008). Chromatin fibers: 30 years of models. In Computational Biology: New Research, A.S. Russe, ed. (Nova Science Publishers), pp. 147164.

7. Schlick, T., Hayes, J., and Grigoryev, S. (2012). Toward convergence of experimental studies and theoretical modeling of the chromatin fiber. J Biol Chem 287, 5183-5191.

8. Grigoryev, S.A., and Woodcock, C.L. (2012). Chromatin organization - the $30 \mathrm{~nm}$ fiber. Exp Cell Res 318, 1448-1455.

9. Luger, K., Dechassa, M.L., and Tremethick, D.J. (2012). New insights into nucleosome and chromatin structure: an ordered state or a disordered affair? Nat Rev Mol Cell Biol 13, 436-447.

10. van Holde, K., and Zlatanova, J. (2007). Chromatin fiber structure: Where is the problem now? Semin Cell Dev Biol 18, 651-658.

11. Staynov, D.Z. (2008). The controversial $30 \mathrm{~nm}$ chromatin fibre. Bioessays 30, 1003-1009.

12. Fussner, E., Strauss, M., Djuric, U., Li, R., Ahmed, K., Hart, M., Ellis, J., and Bazett-Jones, D.P. (2012). Open and closed domains in the mouse genome are configured as 10-nm chromatin fibres. EMBO Rep 13, 992-996.

13. Joti, Y., Hikima, T., Nishino, Y., Kamada, F., Hihara, S., Takata, H., Ishikawa, T., and Maeshima, K. (2012). Chromosomes without a 30-nm chromatin fiber. Nucleus 3, 404-410.

14. Quenet, D., McNally, J.G., and Dalal, Y. (2012). Through thick and thin: the conundrum of chromatin fibre folding in vivo. EMBO Rep 13, 943-944.

15. Ris, H., and Kubai, D.F. (1970). Chromosome structure. Annu Rev Genet 4, 263-294.

16. Pardon, J.F., and Wilkins, M.H. (1972). A super-coil model for nucleohistone. J Mol Biol 68, 115-124.

17. Hewish, D.R., and Burgoyne, L.A. (1973). Chromatin sub-structure. The digestion of chromatin DNA at regularly spaced sites by a nuclear deoxyribonuclease. Biochem Biophys Res Commun $52,504-510$.

18. Kornberg, R.D. (1974). Chromatin structure: a repeating unit of histones and DNA. Science $184,868-871$.

19. Kornberg, R.D., and Thomas, J.O. (1974). Chromatin structure; oligomers of the histones. Science 184, 865-868. 
20. Olins, A.L., and Olins, D.E. (1974). Spheroid chromatin units (v bodies). Science 183, 330-332.

21. Oudet, P., Gross-Bellard, M., and Chambon, P. (1975). Electron microscopic and biochemical evidence that chromatin structure is a repeating unit. Cell 4, 281-300.

22. Olins, D.E., and Olins, A.L. (2003). Chromatin history: our view from the bridge. Nat Rev Mol Cell Biol 4, 809-814.

23. Finch, J.T., and Klug, A. (1976). Solenoidal model for superstructure in chromatin. Proc Natl Acad Sci U S A 73, 1897-1901.

24. Worcel, A., and Benyajati, C. (1977). Higher order coiling of DNA in chromatin. Cell 12, 83100 .

25. Thoma, F., Koller, T., and Klug, A. (1979). Involvement of histone H1 in the organization of the nucleosome and of the salt-dependent superstructures of chromatin. J Cell Biol 83, 403-427.

26. Worcel, A., Strogatz, S., and Riley, D. (1981). Structure of chromatin and the linking number of DNA. Proc Natl Acad Sci U S A 78, 1461-1465.

27. Woodcock, C.L. (1994). Chromatin fibers observed in situ in frozen hydrated sections. Native fiber diameter is not correlated with nucleosome repeat length. J Cell Biol 125, 11-19.

28. Williams, S.P., Athey, B.D., Muglia, L.J., Schappe, R.S., Gough, A.H., and Langmore, J.P. (1986). Chromatin fibers are left-handed double helices with diameter and mass per unit length that depend on linker length. Biophys J 49, 233-248.

29. Dorigo, B., Schalch, T., Kulangara, A., Duda, S., Schroeder, R.R., and Richmond, T.J. (2004). Nucleosome arrays reveal the two-start organization of the chromatin fiber. Science 306, 15711573 .

30. Schalch, T., Duda, S., Sargent, D.F., and Richmond, T.J. (2005). X-ray structure of a tetranucleosome and its implications for the chromatin fibre. Nature 436, 138-141.

31. Lowary, P.T., and Widom, J. (1998). New DNA sequence rules for high affinity binding to histone octamer and sequence-directed nucleosome positioning. J Mol Biol 276, 19-42.

32. Orthaus, S., Klement, K., Happel, N., Hoischen, C., and Diekmann, S. (2009). Linker histone $\mathrm{H} 1$ is present in centromeric chromatin of living human cells next to inner kinetochore proteins. Nucleic Acids Res 37, 3391-3406.

33. Rydberg, B., Holley, W.R., Mian, I.S., and Chatterjee, A. (1998). Chromatin conformation in living cells: support for a zig-zag model of the $30 \mathrm{~nm}$ chromatin fiber. J Mol Biol 284, 71-84.

34. Woodcock, C.L., Grigoryev, S.A., Horowitz, R.A., and Whitaker, N. (1993). A chromatin folding model that incorporates linker variability generates fibers resembling the native structures. Proc Natl Acad Sci U S A 90, 9021-9025.

35. Mozziconacci, J., Lavelle, C., Barbi, M., Lesne, A., and Victor, J.M. (2006). A physical model for the condensation and decondensation of eukaryotic chromosomes. FEBS Lett 580, 368-372.

36. Mozziconacci, J., and Victor, J.M. (2003). Nucleosome gaping supports a functional structure for the 30nm chromatin fiber. J Struct Biol 143, 72-76.

37. Makarov, V., Dimitrov, S., Smirnov, V., and Pashev, I. (1985). A triple helix model for the structure of chromatin fiber. FEBS Lett 181, 357-361. 
38. Engelhardt, M. (2007). Choreography for nucleosomes: the conformational freedom of the nucleosomal filament and its limitations. Nucleic Acids Res 35, e106.

39. Ben-Haim, E., Lesne, A., and Victor, J.M. (2001). Chromatin: a tunable spring at work inside chromosomes. Phys Rev E Stat Nonlin Soft Matter Phys 64, 051921.

40. Barbi, M., Mozziconacci, J., and Victor, J.M. (2005). How the chromatin fiber deals with topological constraints. Phys Rev E Stat Nonlin Soft Matter Phys 71, 031910.

41. Wedemann, G., and Langowski, J. (2002). Computer simulation of the 30-nanometer chromatin fiber. Biophys J 82, 2847-2859.

42. Besker, N., Anselmi, C., and De Santis, P. (2005). Theoretical models of possible compact nucleosome structures. Biophys Chem 115, 139-143.

43. Diesinger, P.M., and Heermann, D.W. (2008). The influence of the cylindrical shape of the nucleosomes and H1 defects on properties of chromatin. Biophys J 94, 4165-4172.

44. Kepper, N., Foethke, D., Stehr, R., Wedemann, G., and Rippe, K. (2008). Nucleosome geometry and internucleosomal interactions control the chromatin fiber conformation. Biophys J.

45. Bednar, J., Horowitz, R.A., Grigoryev, S.A., Carruthers, L.M., Hansen, J.C., Koster, A.J., and Woodcock, C.L. (1998). Nucleosomes, linker DNA, and linker histone form a unique structural motif that directs the higher-order folding and compaction of chromatin. Proc Natl Acad Sci U S A 95, 14173-14178.

46. Besker, N., Anselmi, C., Paparcone, R., Scipioni, A., Savino, M., and De Santis, P. (2003). Systematic search for compact structures of telomeric nucleosomes. FEBS Lett 554, 369-372.

47. Schiessel, H., Gelbart, W.M., and Bruinsma, R. (2001). DNA folding: structural and mechanical properties of the two-angle model for chromatin. Biophys J 80, 1940-1956.

48. Daban, J.R. (2000). Physical constraints in the condensation of eukaryotic chromosomes. Local concentration of DNA versus linear packing ratio in higher order chromatin structures. Biochemistry 39, 3861-3866.

49. Daban, J.R. (2003). High concentration of DNA in condensed chromatin. Biochem Cell Biol 81, 91-99.

50. Daban, J.R., and Bermudez, A. (1998). Interdigitated solenoid model for compact chromatin fibers. Biochemistry 37, 4299-4304.

51. Robinson, P.J., Fairall, L., Huynh, V.A., and Rhodes, D. (2006). EM measurements define the dimensions of the "30-nm" chromatin fiber: evidence for a compact, interdigitated structure. Proc Natl Acad Sci U S A 103, 6506-6511.

52. Katritch, V., Bustamante, C., and Olson, W.K. (2000). Pulling chromatin fibers: computer simulations of direct physical micromanipulations. J Mol Biol 295, 29-40.

53. Arya, G., and Schlick, T. (2006). Role of histone tails in chromatin folding revealed by a mesoscopic oligonucleosome model. Proc Natl Acad Sci U S A 103, 16236-16241.

54. Arya, G., Zhang, Q., and Schlick, T. (2006). Flexible histone tails in a new mesoscopic oligonucleosome model. Biophys J 91, 133-150. 
55. Beard, D.A., and Schlick, T. (2001). Modeling salt-mediated electrostatics of macromolecules: the discrete surface charge optimization algorithm and its application to the nucleosome. Biopolymers 58, 106-115.

56. Sun, J., Zhang, Q., and Schlick, T. (2005). Electrostatic mechanism of nucleosomal array folding revealed by computer simulation. Proc Natl Acad Sci U S A 102, 8180-8185.

57. Zhang, Q., Beard, D.A., and Schlick, T. (2003). Constructing irregular surfaces to enclose macromolecular complexes for mesoscale modeling using the discrete surface charge optimization (DISCO) algorithm. J Comput Chem 24, 2063-2074.

58. Korolev, N., Fan, Y., Lyubartsev, A.P., and Nordenskiold, L. (2012). Modelling chromatin structure and dynamics: status and prospects. Curr Opin Struct Biol 22, 151-159.

59. Korolev, N., Allahverdi, A., Lyubartsev, A.P., and Nordenskiold, L. (2012). The polyelectrolyte properties of chromatin. Soft Matter 8, 9322-9333.

60. Grigoryev, S.A., Arya, G., Correll, S., Woodcock, C.L., and Schlick, T. (2009). Evidence for heteromorphic chromatin fibers from analysis of nucleosome interactions. Proc Natl Acad Sci U S A 106, 13317-13322.

61. Carrivain, P., Cournac, A., Lavelle, C., Lesne, A., Mozziconacci, J., Paillusson, F., Signon, L., Victor, J.M., and Barbi, M. (2012). Electrostatics of DNA compaction in viruses, bacteria and eukaryotes: functional insights and evolutionary perspective. Soft Matter 36, 9285-9301.

62. Wong, H., Victor, J.M., and Mozziconacci, J. (2007). An all-atom model of the chromatin fiber containing linker histones reveals a versatile structure tuned by the nucleosomal repeat length. PLoS ONE 2, e877.

63. Woodcock, C.L., Frado, L.L., and Rattner, J.B. (1984). The higher-order structure of chromatin: evidence for a helical ribbon arrangement. J Cell Biol 99, 42-52.

64. Staynov, D.Z., and Proykova, Y.G. (2008). The sequentiallity of nucleosomes in the $30 \mathrm{~nm}$ chromatin fibre. Febs J 275, 3761-3771.

65. Staynov, D.Z. (2000). DNase I digestion reveals alternating asymmetrical protection of the nucleosome by the higher order chromatin structure. Nucleic Acids Res 28, 3092-3099.

66. Song, F., Chen, P., Sun, D., Wang, M., Dong, L., Liang, D., Xu, R.M., Zhu, P., and Li, G. (2014). Cryo-EM study of the chromatin fiber reveals a double helix twisted by tetranucleosomal units. Science $344,376-380$.

67. Staynov, D.Z. (2008). DNase I footprinting of the nucleosome in whole nuclei. Biochem Biophys Res Commun 372, 226-229.

68. Wu, C., Bassett, A., and Travers, A. (2007). A variable topology for the 30-nm chromatin fibre. EMBO Rep 8, 1129-1134.

69. Depken, M., and Schiessel, H. (2009). Nucleosome shape dictates chromatin fiber structure. Biophys J 96, 777-784.

70. Routh, A., Sandin, S., and Rhodes, D. (2008). Nucleosome repeat length and linker histone stoichiometry determine chromatin fiber structure. Proc Natl Acad Sci U S A 105, 8872-8877. 
71. Woodcock, C.L., Skoultchi, A.I., and Fan, Y. (2006). Role of linker histone in chromatin structure and function: H1 stoichiometry and nucleosome repeat length. Chromosome Res 14, $17-25$.

72. Strauss, F., and Prunell, A. (1982). Nucleosome spacing in rat liver chromatin. A study with exonuclease III. Nucleic Acids Res 10, 2275-2293.

73. Widom, J. (1992). A relationship between the helical twist of DNA and the ordered positioning of nucleosomes in all eukaryotic cells. Proc Natl Acad Sci U S A 89, 1095-1099.

74. Segal, E., Fondufe-Mittendorf, Y., Chen, L., Thastrom, A., Field, Y., Moore, I.K., Wang, J.P., and Widom, J. (2006). A genomic code for nucleosome positioning. Nature 442, 772-778.

75. Valouev, A., Ichikawa, J., Tonthat, T., Stuart, J., Ranade, S., Peckham, H., Zeng, K., Malek, J.A., Costa, G., McKernan, K., et al. (2008). A high-resolution, nucleosome position map of C. elegans reveals a lack of universal sequence-dictated positioning. Genome research 18, 10511063.

76. Valouev, A., Johnson, S.M., Boyd, S.D., Smith, C.L., Fire, A.Z., and Sidow, A. (2011). Determinants of nucleosome organization in primary human cells. Nature 474, 516-520.

77. Tirosh, I., and Barkai, N. (2008). Two strategies for gene regulation by promoter nucleosomes. Genome research 18, 1084-1091.

78. Struhl, K., and Segal, E. (2013). Determinants of nucleosome positioning. Nat Struct Mol Biol 20, 267-273.

79. Zhang, Z., Wippo, C.J., Wal, M., Ward, E., Korber, P., and Pugh, B.F. (2011). A packing mechanism for nucleosome organization reconstituted across a eukaryotic genome. Science $332,977-980$.

80. Riposo, J., and Mozziconacci, J. (2012). Nucleosome positioning and nucleosome stacking: two faces of the same coin. Molecular bioSystems 8, 1172-1178.

81. Fan, Y., Nikitina, T., Zhao, J., Fleury, T.J., Bhattacharyya, R., Bouhassira, E.E., Stein, A., Woodcock, C.L., and Skoultchi, A.I. (2005). Histone H1 depletion in mammals alters global chromatin structure but causes specific changes in gene regulation. Cell 123, 1199-1212.

82. Fan, Y., Nikitina, T., Morin-Kensicki, E.M., Zhao, J., Magnuson, T.R., Woodcock, C.L., and Skoultchi, A.I. (2003). H1 linker histones are essential for mouse development and affect nucleosome spacing in vivo. Mol Cell Biol 23, 4559-4572.

83. Recouvreux, P., Lavelle, C., Barbi, M., Conde, E.S.N., Le Cam, E., Victor, J.M., and Viovy, J.L. (2011). Linker histones incorporation maintains chromatin fiber plasticity. Biophys J 100, 2726-2735.

84. Bussiek, M., Muller, G., Waldeck, W., Diekmann, S., and Langowski, J. (2007). Organisation of nucleosomal arrays reconstituted with repetitive African green monkey alpha-satellite DNA as analysed by atomic force microscopy. Eur Biophys J 37, 81-93.

85. Horz, W., Fittler, F., and Zachau, H.G. (1983). Sequence specific cleavage of African green monkey alpha-satellite DNA by micrococcal nuclease. Nucleic Acids Res 11, 4275-4285.

86. Musich, P.R., Brown, F.L., and Maio, J.J. (1982). Nucleosome phasing and micrococcal nuclease cleavage of African green monkey component alpha DNA. Proc Natl Acad Sci U S A $79,118-122$. 
87. Smith, M.R., and Lieberman, M.W. (1984). Nucleosome arrangement in alpha-satellite chromatin of African green monkey cells. Nucleic Acids Res 12, 6493-6510.

88. Wu, K.C., Strauss, F., and Varshavsky, A. (1983). Nucleosome arrangement in green monkey alpha-satellite chromatin. Superimposition of non-random and apparently random patterns. J Mol Biol 170, 93-117.

89. Beshnova, D.A., Cherstvy, A.G., Vainshtein, Y., and Teif, V.B. (2014). Regulation of the nucleosome repeat length in vivo by the DNA sequence, protein concentrations and long-range interactions. PLoS computational biology 10, e1003698.

90. Hasson, D., Panchenko, T., Salimian, K.J., Salman, M.U., Sekulic, N., Alonso, A., Warburton, P.E., and Black, B.E. (2013). The octamer is the major form of CENP-A nucleosomes at human centromeres. Nat Struct Mol Biol 20, 687-695.

91. Collepardo-Guevara, R., and Schlick, T. (2014). Chromatin fiber polymorphism triggered by variations of DNA linker lengths. Proc Natl Acad Sci U S A 111, 8061-8066.

92. Tremethick, D.J. (2007). Higher-order structures of chromatin: the elusive $30 \mathrm{~nm}$ fiber. Cell $128,651-654$.

93. Eltsov, M., Maclellan, K.M., Maeshima, K., Frangakis, A.S., and Dubochet, J. (2008). Analysis of cryo-electron microscopy images does not support the existence of 30-nm chromatin fibers in mitotic chromosomes in situ. Proc Natl Acad Sci U S A 105, 19732-19737.

94. Maeshima, K., Hihara, S., and Eltsov, M. (2010). Chromatin structure: does the 30-nm fibre exist in vivo? Curr Opin Cell Biol 22, 291-297.

95. Ahmed, K., Dehghani, H., Rugg-Gunn, P., Fussner, E., Rossant, J., and Bazett-Jones, D.P. (2010). Global chromatin architecture reflects pluripotency and lineage commitment in the early mouse embryo. PLoS One 5, e10531.

96. Fussner, E., Djuric, U., Strauss, M., Hotta, A., Perez-Iratxeta, C., Lanner, F., Dilworth, F.J., Ellis, J., and Bazett-Jones, D.P. (2011). Constitutive heterochromatin reorganization during somatic cell reprogramming. EMBO J 30, 1778-1789.

97. Bian, Q., and Belmont, A.S. (2012). Revisiting higher-order and large-scale chromatin organization. Curr Opin Cell Biol 24, 359-366.

98. Poirier, M.G., Oh, E., Tims, H.S., and Widom, J. (2009). Dynamics and function of compact nucleosome arrays. Nat Struct Mol Biol 16, 938-944.

99. Rego, A., Sinclair, P.B., Tao, W., Kireev, I., and Belmont, A.S. (2008). The facultative heterochromatin of the inactive $\mathrm{X}$ chromosome has a distinctive condensed ultrastructure. J Cell Sci $121,1119-1127$.

100. Pepenella, S., Murphy, K.J., and Hayes, J.J. (2014). Intra- and inter-nucleosome interactions of the core histone tail domains in higher-order chromatin structure. Chromosoma 123, 3-13.

101. Kan, P.Y., Caterino, T.L., and Hayes, J.J. (2009). The H4 tail domain participates in intra- and internucleosome interactions with protein and DNA during folding and oligomerization of nucleosome arrays. Mol Cell Biol 29, 538-546.

102. Kan, P.Y., Lu, X., Hansen, J.C., and Hayes, J.J. (2007). The H3 tail domain participates in multiple interactions during folding and self-association of nucleosome arrays. Mol Cell Biol 27, 2084-2091. 
103. Zheng, C., Lu, X., Hansen, J.C., and Hayes, J.J. (2005). Salt-dependent intra- and internucleosomal interactions of the $\mathrm{H} 3$ tail domain in a model oligonucleosomal array. J Biol Chem 280, 33552-33557.

104. Stehr, R., Kepper, N., Rippe, K., and Wedemann, G. (2008). The effect of internucleosomal interaction on folding of the chromatin fiber. Biophys J 95, 3677-3691.

105. Hihara, S., Pack, C.G., Kaizu, K., Tani, T., Hanafusa, T., Nozaki, T., Takemoto, S., Yoshimi, T., Yokota, H., Imamoto, N., et al. (2012). Local nucleosome dynamics facilitate chromatin accessibility in living mammalian cells. Cell reports 2, 1645-1656.

106. Nozaki, T., Kaizu, K., Pack, C.G., Tamura, S., Tani, T., Hihara, S., Nagai, T., Takahashi, K., and Maeshima, K. (2013). Flexible and dynamic nucleosome fiber in living mammalian cells. Nucleus 4, 349-356.

107. Langowski, J., and Heermann, D.W. (2007). Computational modeling of the chromatin fiber. Semin Cell Dev Biol 18, 659-667.

108. Lavelle, C., and Benecke, A. (2006). Chromatin physics: Replacing multiple, representationcentered descriptions at discrete scales by a continuous, function-dependent self-scaled model. Eur Phys J E Soft Matter 19, 379-384.

109. Lavelle, C. (2009). Forces and torques in the nucleus: chromatin under mechanical constraints. Biochem Cell Biol 87, 307-322.

110. Diesinger, P.M., Kunkel, S., Langowski, J., and Heermann, D.W. (2010). Histone depletion facilitates chromatin loops on the kilobasepair scale. Biophys J 99, 2995-3001.

111. Volle, C., and Dalal, Y. (2014). Histone variants: the tricksters of the chromatin world. Curr Opin Genet Dev 25, 8-14,138.

112. Weber, C.M., and Henikoff, S. (2014). Histone variants: dynamic punctuation in transcription. Genes Dev 28, 672-682.

113. Zentner, G.E., and Henikoff, S. (2013). Regulation of nucleosome dynamics by histone modifications. Nat Struct Mol Biol 20, 259-266.

114. Sivolob, A., Lavelle, C., and Prunell, A. (2003). Sequence-dependent nucleosome structural and dynamic polymorphism. Potential involvement of histone $\mathrm{H} 2 \mathrm{BN}$-terminal tall proximal domain. Journal of Molecular Biology 326, 49-63.

115. Lavelle, C. (2014). Pack, unpack, bend, twist, pull, push: the physical side of gene expression. Curr Opin Genet Dev 25, 74-84.

116. Rando, O.J., and Chang, H.Y. (2009). Genome-wide views of chromatin structure. Annu Rev Biochem 78, 245-271.

117. Dekker, J. (2008). Mapping in vivo chromatin interactions in yeast suggests an extended chromatin fiber with regional variation in compaction. J Biol Chem 283, 34532-34540.

118. Carlson, R.D., and Olins, D.E. (1976). Chromatin model calculations: Arrays of spherical nu bodies. Nucleic Acids Res 3, 89-100.

119. McGhee, J.D., Nickol, J.M., Felsenfeld, G., and Rau, D.C. (1983). Higher order structure of chromatin: orientation of nucleosomes within the $30 \mathrm{~nm}$ chromatin solenoid is independent of species and spacer length. Cell 33, 831-841. 
120. Butler, P.J. (1984). A defined structure of the $30 \mathrm{~nm}$ chromatin fibre which accommodates different nucleosomal repeat lengths. Embo J 3, 2599-2604.

121. Dubochet, J., Adrian, M., Schultz, P., and Oudet, P. (1986). Cryo-electron microscopy of vitrified SV40 minichromosomes: the liquid drop model. Embo J 5, 519-528.

122. Fajkus, J., and Trifonov, E.N. (2001). Columnar packing of telomeric nucleosomes. Biochem Biophys Res Commun 280, 961-963.

123. Stein, A. (1980). DNA wrapping in nucleosomes. The linking number problem re-examined. Nucleic Acids Res 8, 4803-4820.

124. Bordas, J., Perez-Grau, L., Koch, M.H., Vega, M.C., and Nave, C. (1986). The superstructure of chromatin and its condensation mechanism. II. Theoretical analysis of the X-ray scattering patterns and model calculations. Eur Biophys J 13, 175-185.

125. Leuba, S.H., Yang, G., Robert, C., Samori, B., van Holde, K., Zlatanova, J., and Bustamante, C. (1994). Three-dimensional structure of extended chromatin fibers as revealed by tappingmode scanning force microscopy. Proc Natl Acad Sci U S A 91, 11621-11625.

126. Friedland, W., Jacob, P., Paretzke, H.G., and Stork, T. (1998). Monte Carlo simulation of the production of short DNA fragments by low-linear energy transfer radiation using higher-order DNA models. Radiat Res 150, 170-182.

127. Martino, J.A., Katritch, V., and Olson, W.K. (1999). Influence of nucleosome structure on the three-dimensional folding of idealized minichromosomes. Structure 7, 1009-1022.

128. Bernhardt, P., Friedland, W., Jacob, P., and Paretzke, H.G. (2003). Modeling of ultrasoft X-ray induced DNA damage using structured higher order DNA targets. International Journal of Mass Spectrometry 579-597.

129. Staynov, D.Z., and Proykova, Y.G. (2008). Topological constraints on the possible structures of the $30 \mathrm{~nm}$ chromatin fibre. Chromosoma 117, 67-76.

130. Scheffer, M.P., Eltsov, M., and Frangakis, A.S. (2011). Evidence for short-range helical order in the 30-nm chromatin fibers of erythrocyte nuclei. Proc Natl Acad Sci U S A 108, 1699216997.

131. Aumann, F., Lankas, F., Caudron, M., and Langowski, J. (2006). Monte Carlo simulation of chromatin stretching. Phys Rev E Stat Nonlin Soft Matter Phys 73, 041927.

132. Friedland, W., Paretzke, H.G., Ballarini, F., Ottolenghi, A., Kreth, G., and Cremer, C. (2008). First steps towards systems radiation biology studies concerned with DNA and chromosome structure within living cells. Radiat Environ Biophys 47, 49-61.

133. Kepper, N., Ettig, R., Stehr, R., Marnach, S., Wedemann, G., and Rippe, K. (2011). Force spectroscopy of chromatin fibers: extracting energetics and structural information from Monte Carlo simulations. Biopolymers 95, 435-447.

134. Collepardo-Guevara, R., and Schlick, T. (2012). Crucial role of dynamic linker histone binding and divalent ions for DNA accessibility and gene regulation revealed by mesoscale modeling of oligonucleosomes. Nucleic Acids Res 40, 8803-8817.

135. Victor, J.M., Zlatanova, J., Barbi, M., and Mozziconacci, J. (2012). Pulling chromatin apart: Unstacking or Unwrapping? BMC biophysics 5, 21. 
136. Widom, J., and Klug, A. (1985). Structure of the 300A chromatin filament: X-ray diffraction from oriented samples. Cell 43, 207-213.

137. Giannasca, P.J., Horowitz, R.A., and Woodcock, C.L. (1993). Transitions between in situ and isolated chromatin. J Cell Sci 105 ( Pt 2), 551-561.

138. Athey, B.D., Smith, M.F., Rankert, D.A., Williams, S.P., and Langmore, J.P. (1990). The diameters of frozen-hydrated chromatin fibers increase with DNA linker length: evidence in support of variable diameter models for chromatin. J Cell Biol 111, 795-806.

139. Alegre, C., and Subirana, J.A. (1989). The diameter of chromatin fibres depends on linker length. Chromosoma 98, 77-80. 


\section{Legends to the figures}

Fig. 1: electron microscopy view of chromatin fibers

(A) Low (left) and high (right) ionic-strength chromatin spread (bar 30nm; adapted from [22], by courtesy of the authors). While every nucleosome is visible in the beads-on-a-string conformation (left), their assembly into a more dense fiber does not enable to visualize the path of the DNA in this compact structure. 40 years of modelling have followed since to decipher this path, participating to the evergrowing literature on this elusive "chromatin fiber". (B): number of paper per year with "chromatin fiber" as the subject.

Fig. 2: a (very selective) gallery of chromatin models

(A) schematic models, adapted from a [118]; b [23]; c [25]; d [119]; e [63]; f [120]; g [121]; h [122].

(B) hand-made models, adapted from a [24]; b [123]; c [26]; d [28]; e [37]; f [38]. (C) geometrical/analytical models, adapted from a [124]; b [34]; c [125]; d [45]; e [126]; f [49, 50]; g [127]; h [39]; i [36]; j [128]; k [40]; 1 [29]; m [30]; n [51]; o [68]; p [129]; q [66]; r [130]. (D) computational/numerical models, adapted from a [52], b [55]; c [41]; d [46]; e [42]; f [56]; g [131]; h [53, 54]; i [62]; j [43]; k [44]; 1 [132]; m [60]; n [110]; o [133]; p [134]; q [135]; r [91]. Pictures are dispatched in chronological order in each category. Note that only some of these models take into account the linker histone, either implicitly (A: c, e; B: a, c; C: d, e, f, i, k; D: a, c, e, g, j, k, n) or explicitly (C: j, q; D: i, m, p, r).

Figure 3. Classification of the various compact chromatin models in regard with nucleosomal distribution.

A nomenclature is proposed to classify one start (solenoid) to five starts helices models.

Figure 4. Relationship between fiber diameter and linker length according to the source of material and imaging technique used.

(Left panel) in situ fibers; (central panel) isolated fibers; (right panel) reconstituted fibers. EM stands for Electron Microscopy experiments, EM-fixed indicates the use of fixative agent to prepare chromatin, $\mathrm{X}$-rays indicates the use of X-ray diffraction measurements. Data were compiled from $[25,27,28,51$, $66,136-139]$. 
Fig. 1

A
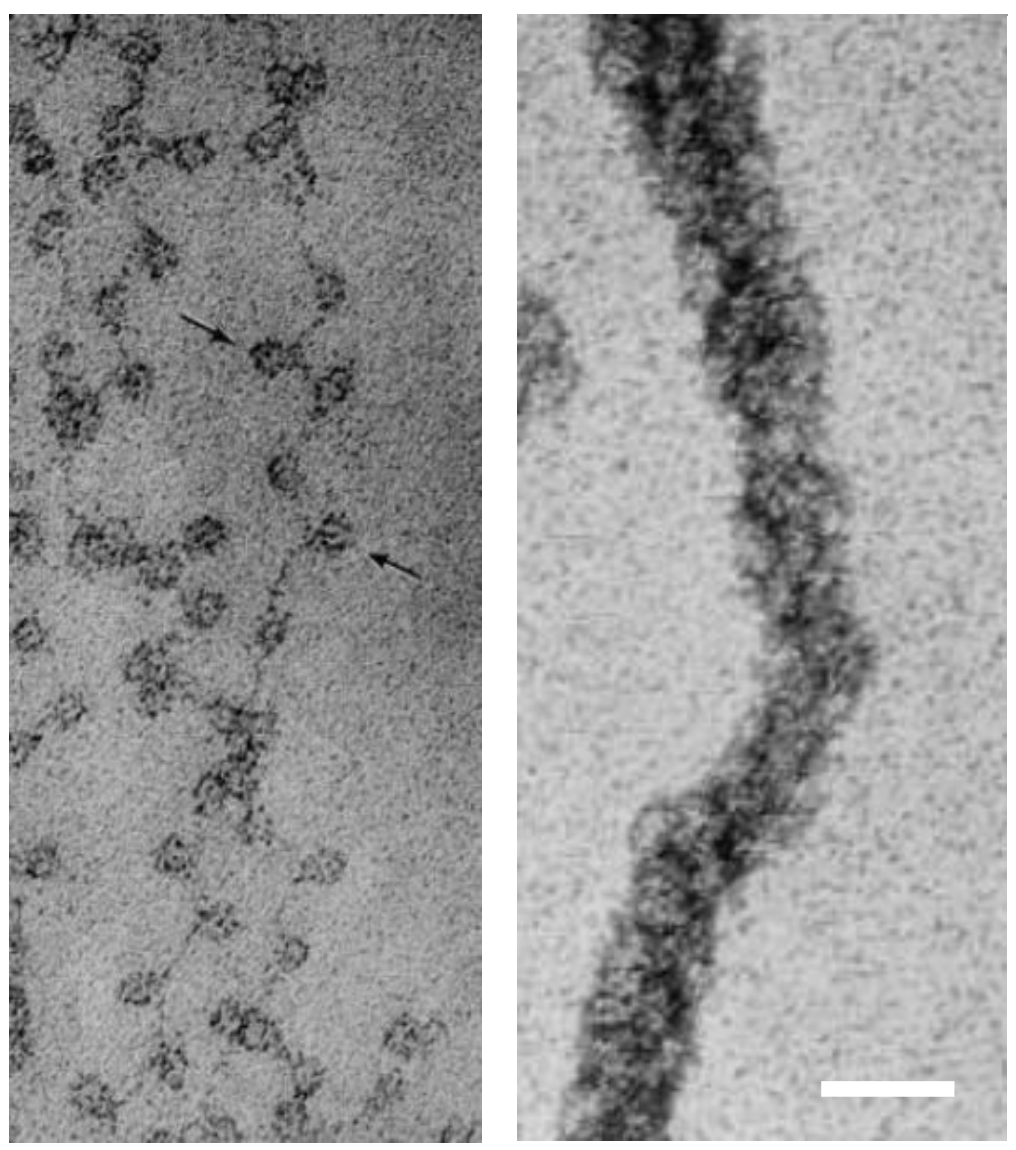

B

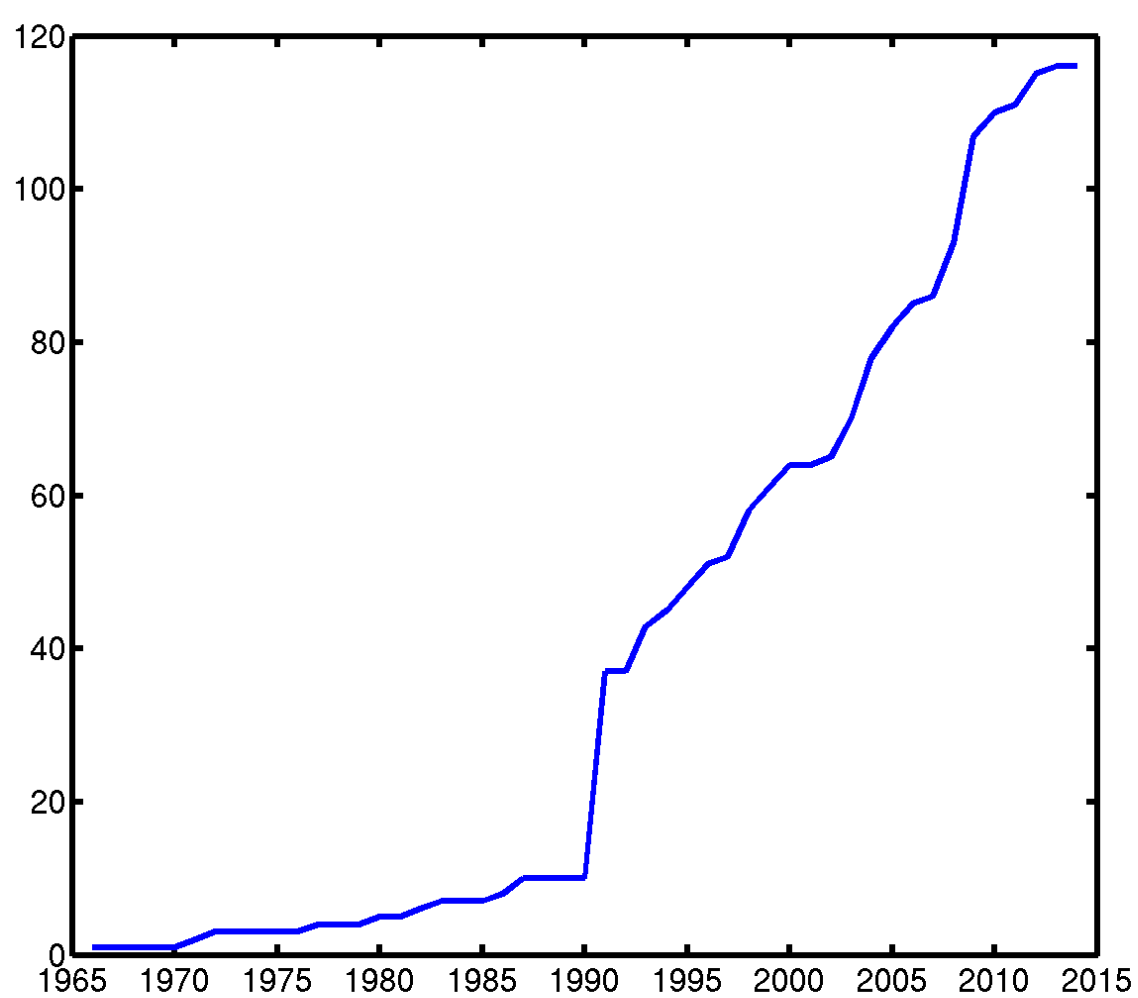


Fig. 2

A

B

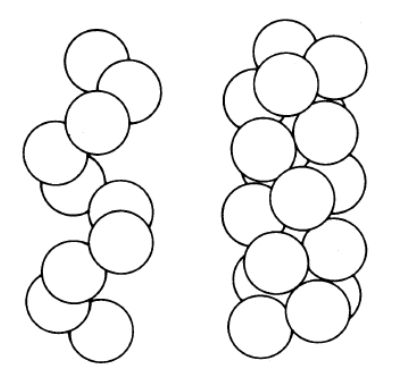

a

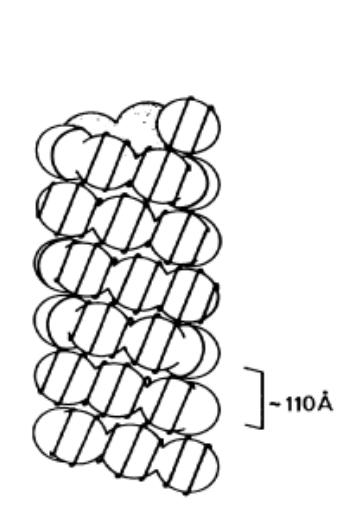

b

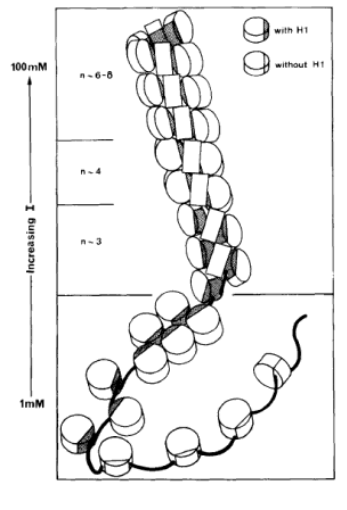

C

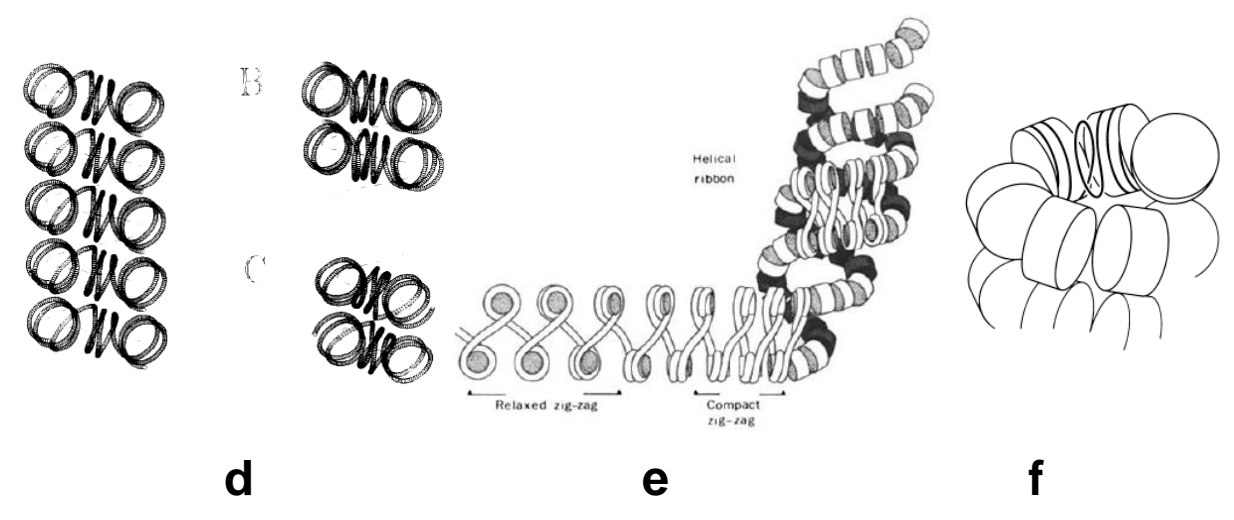

30
2
2
0

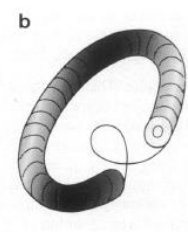

ofo

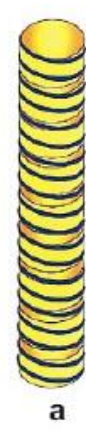

g

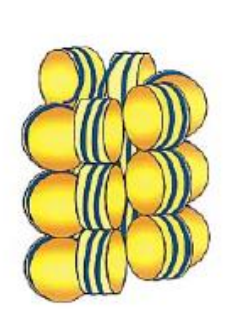

b

h
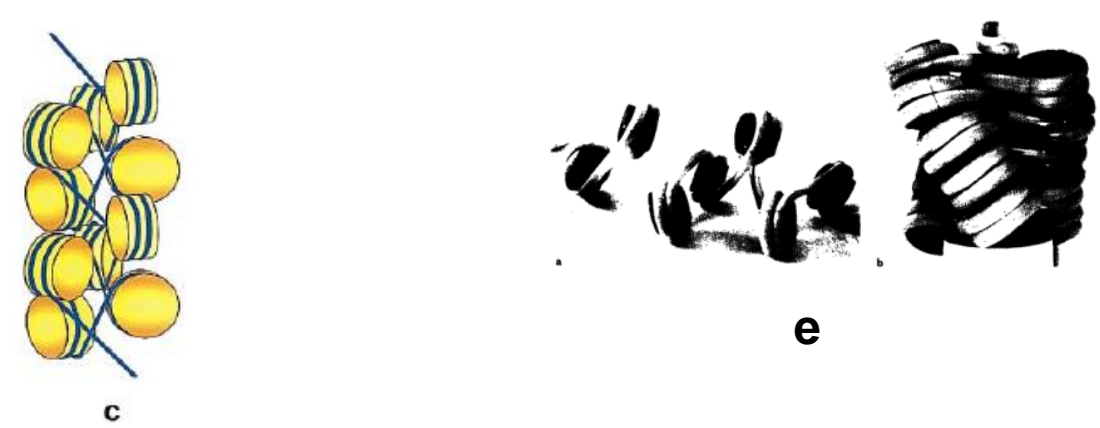

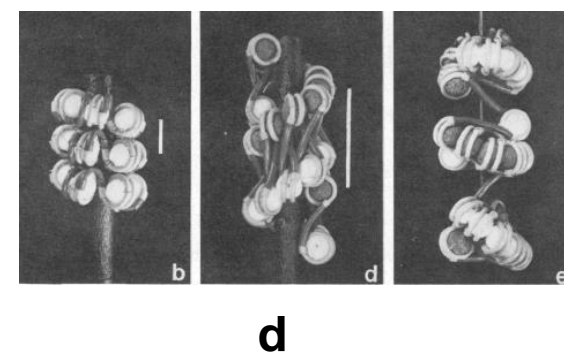

b

C

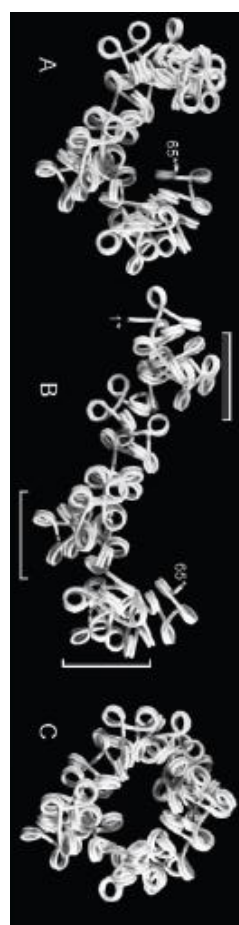

f 
Fig. 3

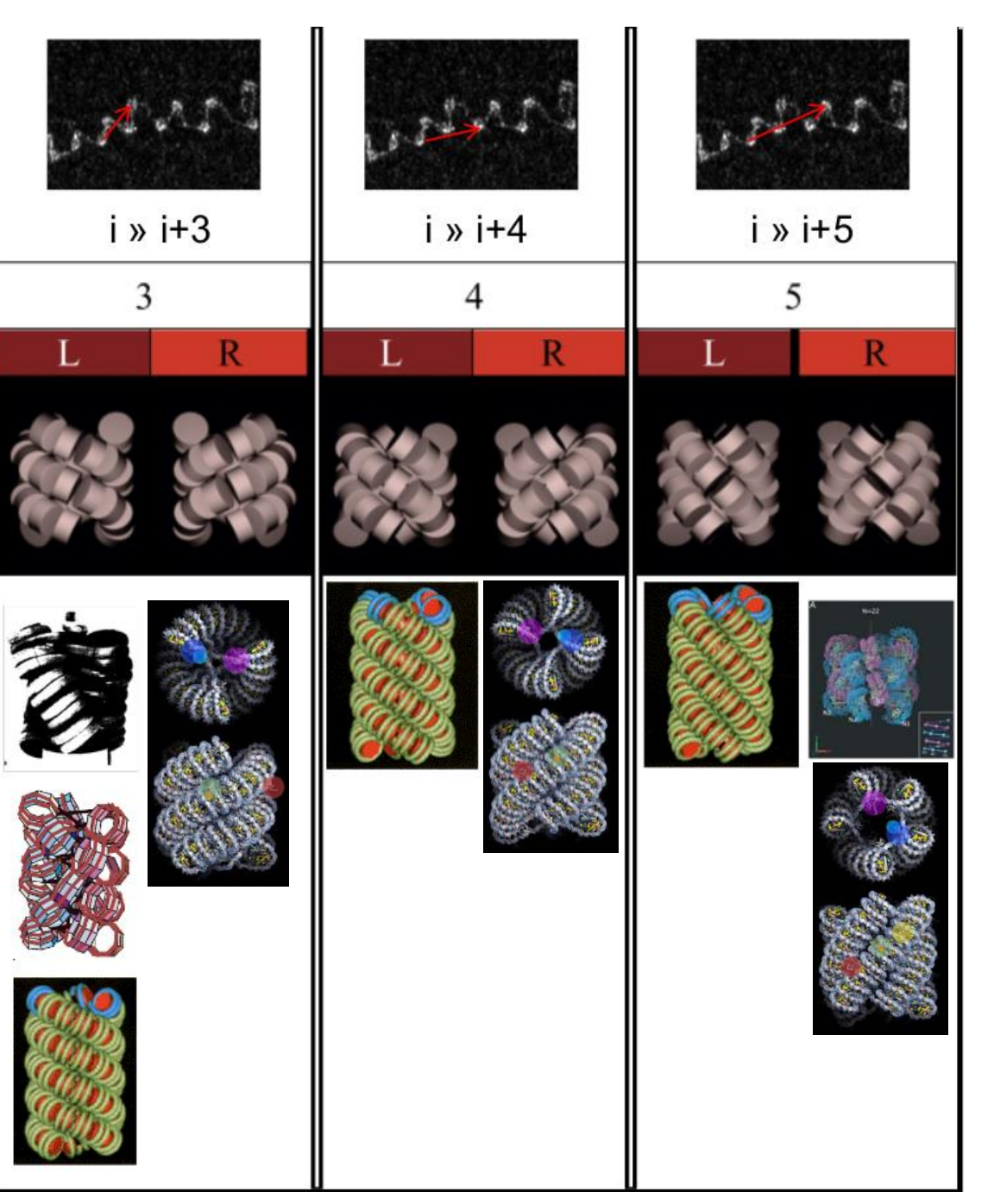

$D=\alpha * \ell+\beta$
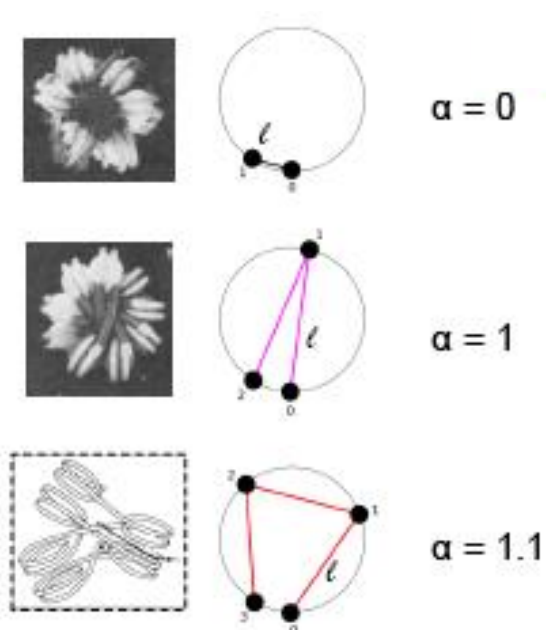

$a=1.1$

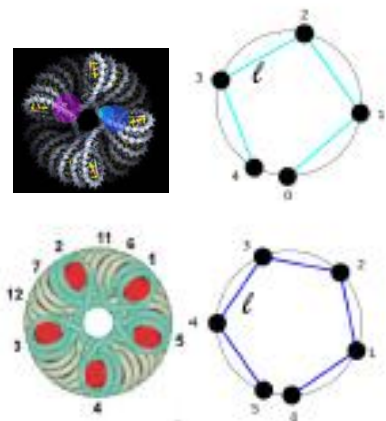

$a=1.6$

$\alpha=1.4$

(<smiles>[AlH]=[Ti]</smiles>

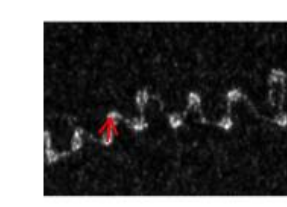

$\frac{\mathrm{i} \text { » i+1 }}{1}$

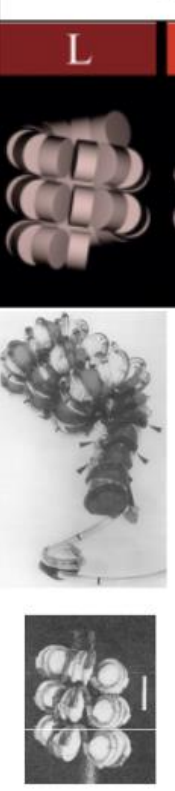

os

R

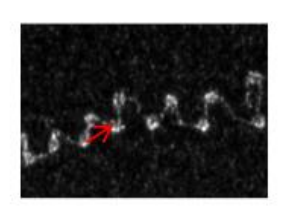

i » i+2

2

\begin{tabular}{|l|l|}
\hline \multicolumn{2}{|l|}{2} \\
\hline $\mathrm{L}$ & $\mathrm{R}$ \\
\hline
\end{tabular}

(27) $(-)$, $(x) \leq 1)$

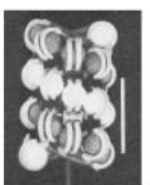

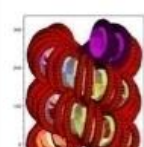

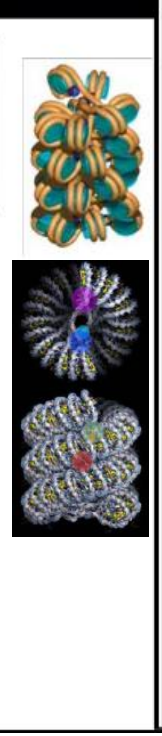


Fig. 4

\section{a}

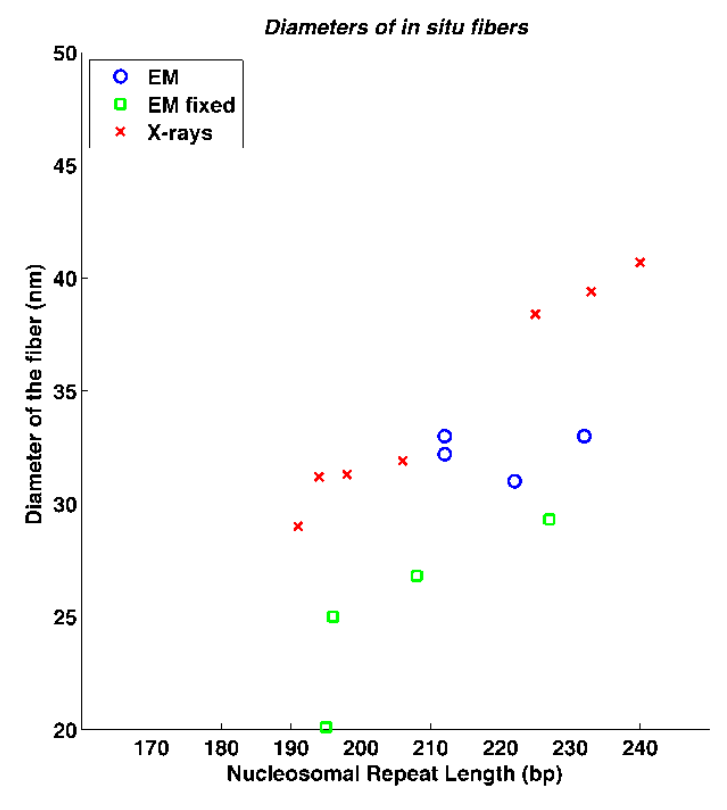

b

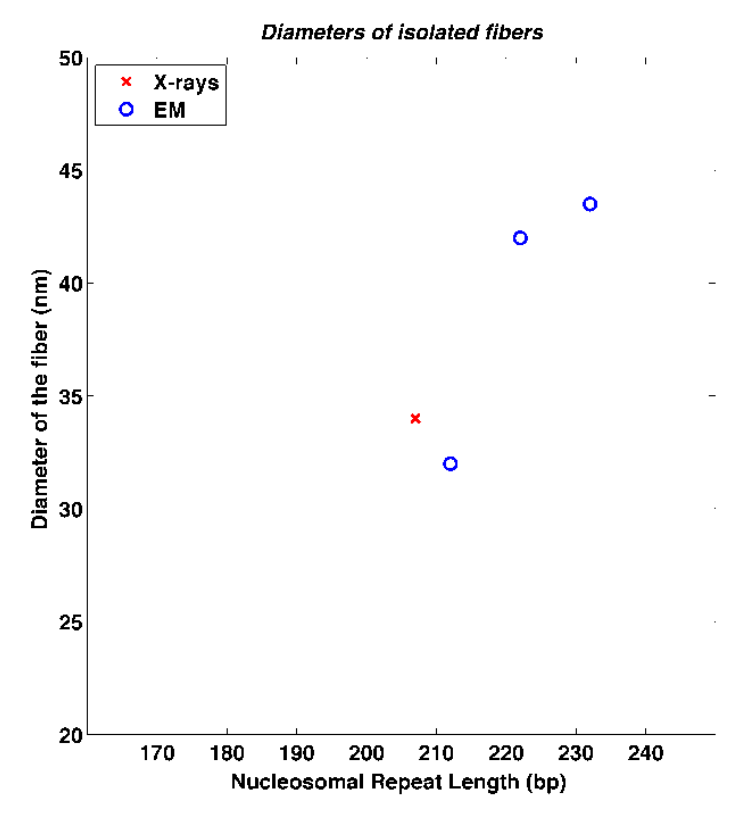

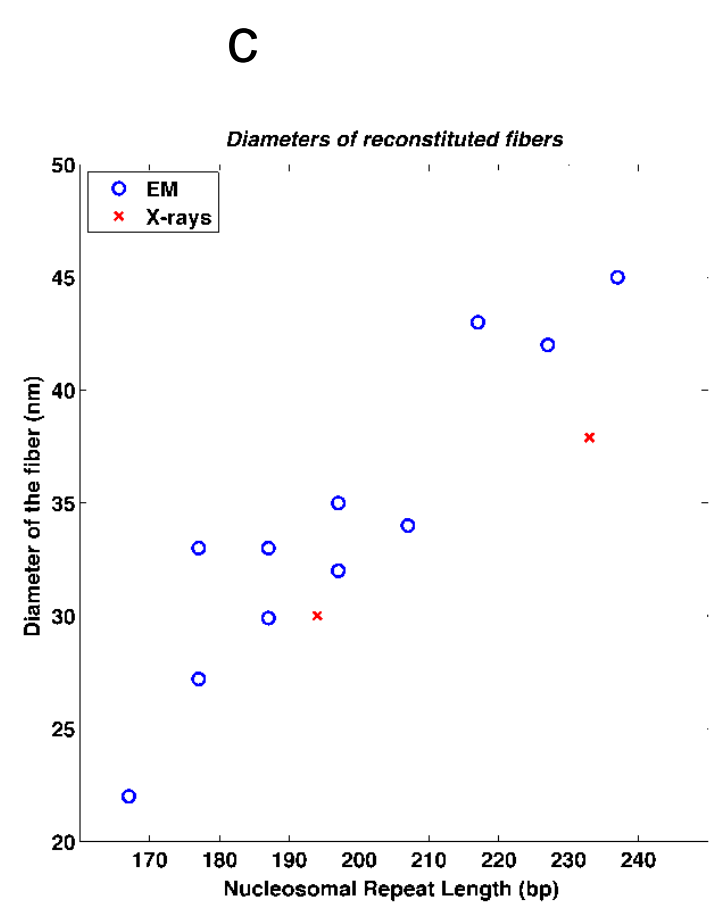

